Original Research Paper

\title{
Measurement of Gas-Phase Mass Transfer Coefficients in a Humidification Column through Random Packing
}

\author{
${ }^{1}$ Masoud Khorasani, ${ }^{1}$ Morteza Zivdar, ${ }^{1}$ Farshad Fashchi Tabrizi, ${ }^{2}$ Zahra Askari, \\ ${ }^{3}$ Kaveh Ostad-Ali-Askari, ${ }^{4}$ Vijay P. Singh, ${ }^{5}$ Saeid Eslamian and ${ }^{6}$ Mohsen Ghane \\ ${ }^{I}$ Chemistry Engineering Faculty, Sistan and Balouchestan University, Zahedan, Iran \\ ${ }^{2}$ Master of Agriculture Engineering, University of ShahreKord, Iran \\ ${ }^{3}$ Department of Civil Engineering, Isfahan (Khorasgan) Branch, Islamic Azad University, Isfahan, Iran \\ ${ }^{4}$ Department of Biological and Agricultural Engineering and Zachry \\ Department of Civil Engineering, Texas $A$ and $M$ University, \\ 321 Scoates Hall, 2117 TAMU, College Station, Texas 77843-2117, USA \\ ${ }^{5}$ Department of Water Engineering, Isfahan University of Technology, Isfahan, Iran \\ ${ }^{6}$ Department of Civil Engineering, South Tehran Branch, Islamic Azad University, Tehran, Iran
}

\author{
Article history \\ Received: 30-04-2018 \\ Revised: 31-05-2018 \\ Accepted: 17-07-2019 \\ Corresponding Author: \\ Kaveh Ostad-Ali-Askari \\ Department of Civil \\ Engineering, Isfahan \\ (Khorasgan) Branch, Islamic \\ Azad University, Isfahan, Iran \\ Email: koa.askari@khuisf.ac.ir
}

\begin{abstract}
Packed columns are an important part of the broad selection of mass and heat transfer equipment. Nowadays, the use of packed columns is increasing, which is because of its lower pressure drop, higher capacity and higher mass transfer in comparison to tray columns. The experiential tests and the hypothetical analysis display that the chemical dehumidification of air by hygroscopic salt solutions confirms the stable reduction in humidity ratio, which is appropriate for uses to air conditioning or drying processes The mass transfer factors in the pulse were found to correspond nearly to the factors that would be achieved in the distributed bubble flow regime In the present study, parameters that affect column performance, such as, fluid retention and gas-phase mass transfer coefficient in a humidification column using random packing in towers with $0.1 \mathrm{~m}$ and $0.2 \mathrm{~m}$ diameters and $1 \mathrm{~m}$ height, were measured Air velocity was 1.32 to $3.92 \mathrm{~m}^{3}$ per hour and liquid velocity was 10 to $70 \mathrm{~m}^{3}$ per hour. In this research, the Nakajima model was used to calculate the effective area. Thereafter, experimental values for gas-phase mass transfer coefficients were compared to Zech, Shi, Grouff, Shulman, Billet and Ondamodels The mean relative errors of these models with the present study's experimental findings were $7 \%, 15 \%, 29 \%$, $21 \%, 45 \%$ and $195 \%$. Findings showed that by decreasing the column diameter, the gas-phase mass transfer coefficient $\left(\mathrm{K}_{\mathrm{g}}\right.$.ae) also increases Further, the obtained retention values showed that retention in the column with a $0.1 \mathrm{~m}$ diameter was higher than the column with a $0.2 \mathrm{~m}$ column.
\end{abstract}

Keywords: Packed Column, Random Packing, Mass Transfer Coefficients, Effective Area, Liquid Retention, Humidification Column

\section{Introduction}

Many different types of research and studies by scientific organizations and packing manufacturing companies on random packing was initiated in 1930 (Gładyszewski and Skiborowski, 2018). Mass transfer relations have been stated based on theoretical data that have different operational accuracies, limitations and ranges (Treybal, 1968; Shulman and de Gouff, 1915). In this study, mass transfer relations and parameters that are depended upon these relations such as mass transfer effective area, are presented, then the experimental values are presented and compared to these models (Sugiyama et al., 2008). Heating or cooling of major surface region products is often made in systems containing of arrays of round or slot nozzles, through 
which air affects vertically upon the product surface. The alteration of local transfer ratios is graphically shown. It also inspects how to use these equations in the heat exchanger and dryer plan as well as in optimization. External variables affecting heat and mass transfer in influencing flow relies on mass flow rate, kind and state of the gas and on the figure, size and position of the nozzles relative to each other and to the solid area (Fan et al., 2018). The aim of this evaluation paper is to summarize the significant published articles on the increase of the forced convection heat transfer (Darakchiev et al., 2016). This article describes a general survey accentuating the engineering requests and experimental equations, offered for the prediction of heat and mass transfer coefficients within a great and technologically essential range of inconstants (Schaefer et al., 1997). Heating or cooling of great surface zone supplys is often carried out in devices including of arrays of round or slot nozzles, through which air effects vertically upon the product surface (Zhang, 2012). The alteration of local transfer factors is graphically demonstrated. It also investigates how to use these equations in heat exchanger and dryer design as well as in optimization (Coker, 2010). The flow field of affecting flow is diagrammatically showed. External uncertain affecting heat and mass transfer in influencing flow relies on mass flow rate, kind and state of the gas and on the figure, size and position of the nozzles relative to each other and to the solid surface (Kishimoto et al., 2011). The plan of high-proficiency arrays of nozzles is also considered. The airflow is laminar and constant and has a temperature much higher than the water, causing a composed heat and mass transfer attended with water evaporation into the airstream. Computations are performance with and without attention of the air property alterations caused by the air temperature and humidity alters near the water surface and in the airflow direction. The consequences display that the heat and mass transfer factors both diminish with enhancing water surface temperature, i.e., enhancing mass flux. The air property variation has a significant and intricate relic on heat transfer factor but an inconspicuous effect on mass transfer factor (Goldstein et al., 2006).

The experiential set-up is fully demonstrated together with measurements, methods, data reduction and precision. A scientific model of the packed column and the respective simulation computer code was extended to anticipate the implementation of the system and to analysis the system sensitivity to the primary running parameters (Wang et al., 2007). The consequences disclose a large temperature drops at the wall area and the temperature drop relies on the axial distance from the inlet. In this procedure, this instrument allows the taking of mean and oscillating flow and temperature values at any point of the bed. Relationships for the total pressure drop, the pressure drop across the pulse and for the pulse velocity are received. The ratio of the vaporization to absorption factor, accurate for diversities in diffusivity, is found to be immediately proportional to the ratio of the total holdup to the running holdup in verification of the presented model in which the effective interfacial zone for each type of running is proportional to the holdup of the liquid active for that performance (Weiss and Wieltsch, 2005). Computational fluid dynamics as a simulation tool permits taking a more particularitied view of the fluid flow and heat transfer mechanisms in fixed-bed reactors, through the resolution of $3 \mathrm{D}$ Reynolds averaged transport equations, together with a turbulence model while required (Peychès-Bach et al., 2009; Bartelmus et al., 1998). Column applying water vaporization and methanol sorption (Sun et al., 2011). One of the effective parameters on mass transfer is the effective interfacial area. In these experiments, water and air were used as liquid and gas phase (Aferka et al., 2011).

\section{Materials and Method}

\section{Mass Transfer Coefficients Measurement Method}

In order to obtain mass transfer coefficients, first the number of NTU transfer units should be calculated and in the present study, the Adiabatic Humidification method was used ( $\mathrm{Xu}$ et al., 2015). This is a very unique state in which the liquid is entered into the system at the input gas's adiabatic saturation temperature (Andreev et al., 2007). This transformation can be conducted by continuously entering the column's output liquid (without adding or reducing its heat) into the column (Zaidiza et al., 2015). For preventing heat loss, the column has been insulated (Shulman et al., 1955; Onda et al., 1968). Air is cooled in an adiabatic humidification procedure and then in turn, the similar air is applied to decrease - via a heat exchanger - the temperature of the second stream of air, whose moisture content accordingly persists unaltered (Zhang et al., 2010). The cooling outcome is individually intense when the air to be humidified is the ambient air being released. A way and device for heat and mass transfer are related applying a moving gas, such as air at a fixed and atmospheric pressure, to prepare a continual change in a vapour-liquid equilibrium between accurate but regularly changing gas and liquid temperatures within energy transferring chambers (Seibert et al., 2011). The heat exchanger prepares for heat transfer between the first and the second substance materials of corresponding parts of the first and second chambers. This heat conduct can 
permit condensation causing further evaporation in the corresponding chamber sector terminating in reusing of energy (Li et al., 2006). Simultaneous with the temperature differences, the fragment wetting can further let wetting substance condensations caused by evaporation, selective concentration, or sorption to alter between wetted parts. Using experimental relationships to evaluates different parameters applied in a mathematical model is unavoidable (Gómez-Castro et al., 2018). In this article, a mathematical model is extended for a packed-bed air dehumidifier and the effect of some popular experimental relationships existent in literature is assessed on the model's predictions and precision (Longo and Gasparella, 2005).

\section{Gas-Phase Mass Transfer Coefficients}

In our experiments, the column's diameter was 0.2 $\mathrm{m}$, its height was $1 \mathrm{~m}$, the liquid phase was water and the gas phase was air and the air velocity was 1.32 to $3.93 \mathrm{~m}^{3}$ per second and were performed in four liquid velocities of $10,30,50$ and $70 \mathrm{~m}^{3}$ per hour. The thermometer's accuracy in the laboratory was +0.1 centigrade degrees (Parrish and Fehsenfeld, 2000).

The used packing was a $16 \mathrm{~mm}$ plastic Paul ring packing, which Fig. 1 is an image of this packing in different views. In Table 1 , the specifications of this packing is shown.
The number of $\mathrm{NTU}_{\mathrm{g}}$ transfer units were obtained through measurement of the temperatures. Figures 2 and 3 the $\mathrm{HTU}_{\mathrm{g}}$ per $\mathrm{F}_{\mathrm{g}}$ graph for gas capacity coefficient and mass transfer coefficients are shown, respectively $\left(F_{s}=\right.$ $u_{g s} \sqrt{\rho_{g}}$ ) (Dubrawski et al., 2013).

Table 1: Plastic Paul ring packing specifications

\begin{tabular}{ll}
\hline$\varepsilon(\%)$ & $\mathrm{a}_{\mathrm{p}}\left(\mathrm{m}^{2} / \mathrm{m}^{3}\right)$ \\
\hline 87 & 341 \\
\hline
\end{tabular}

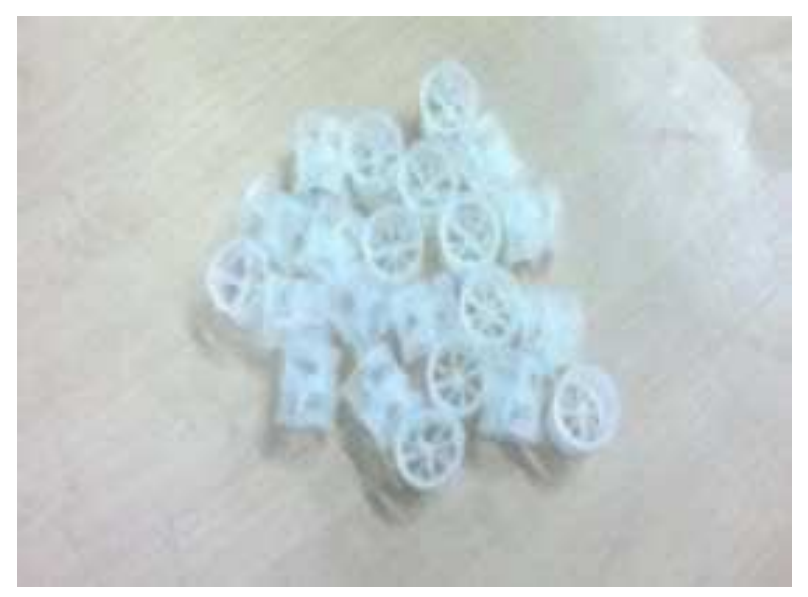

Fig. 1: Plastic paul ring packing used in this experiment

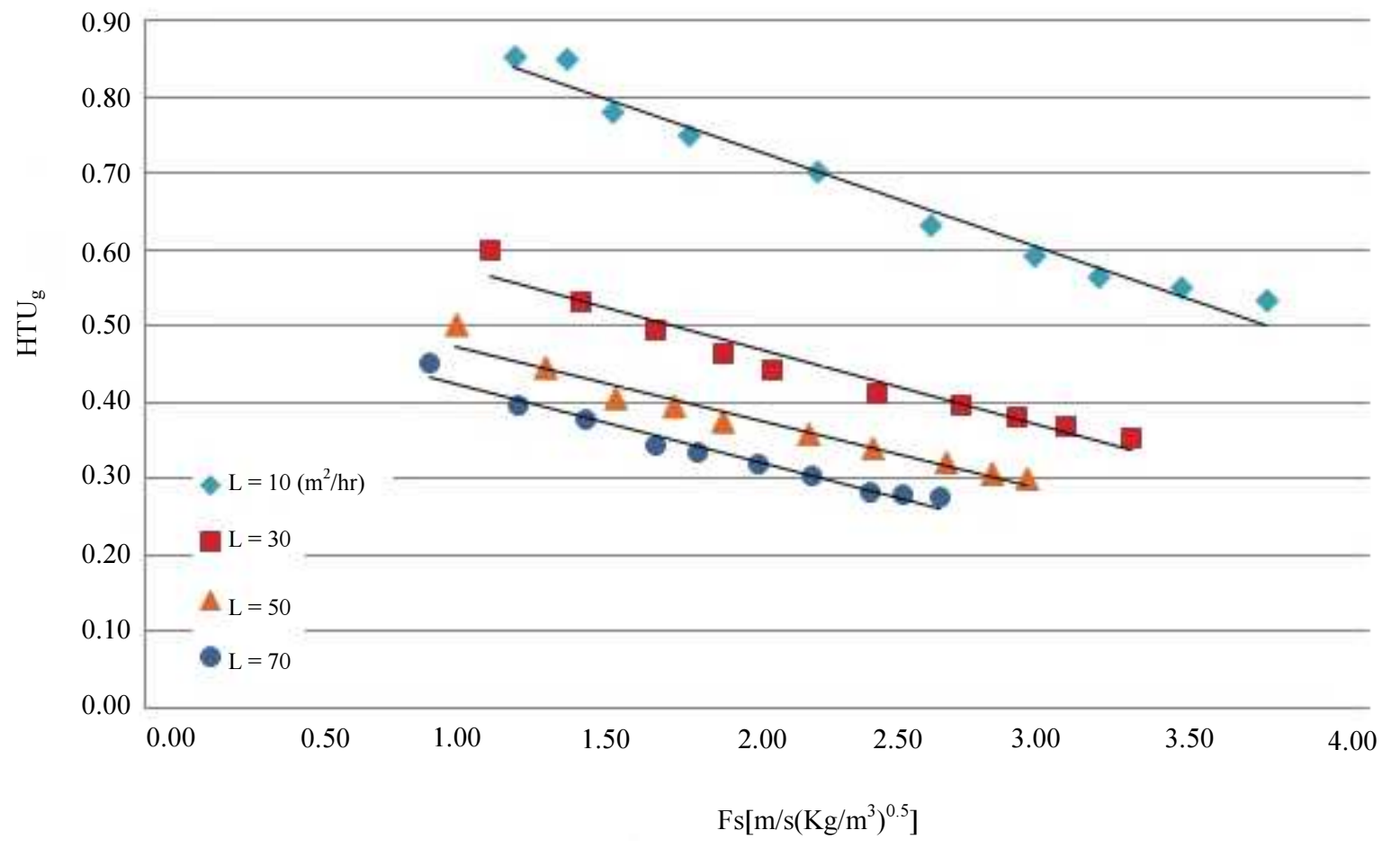

Fig. 2: $\mathrm{HTU}_{\mathrm{g}}$ per $F_{\mathrm{g}}$ graph for gas capacity, $0.2 \mathrm{~m}$ column diameter 


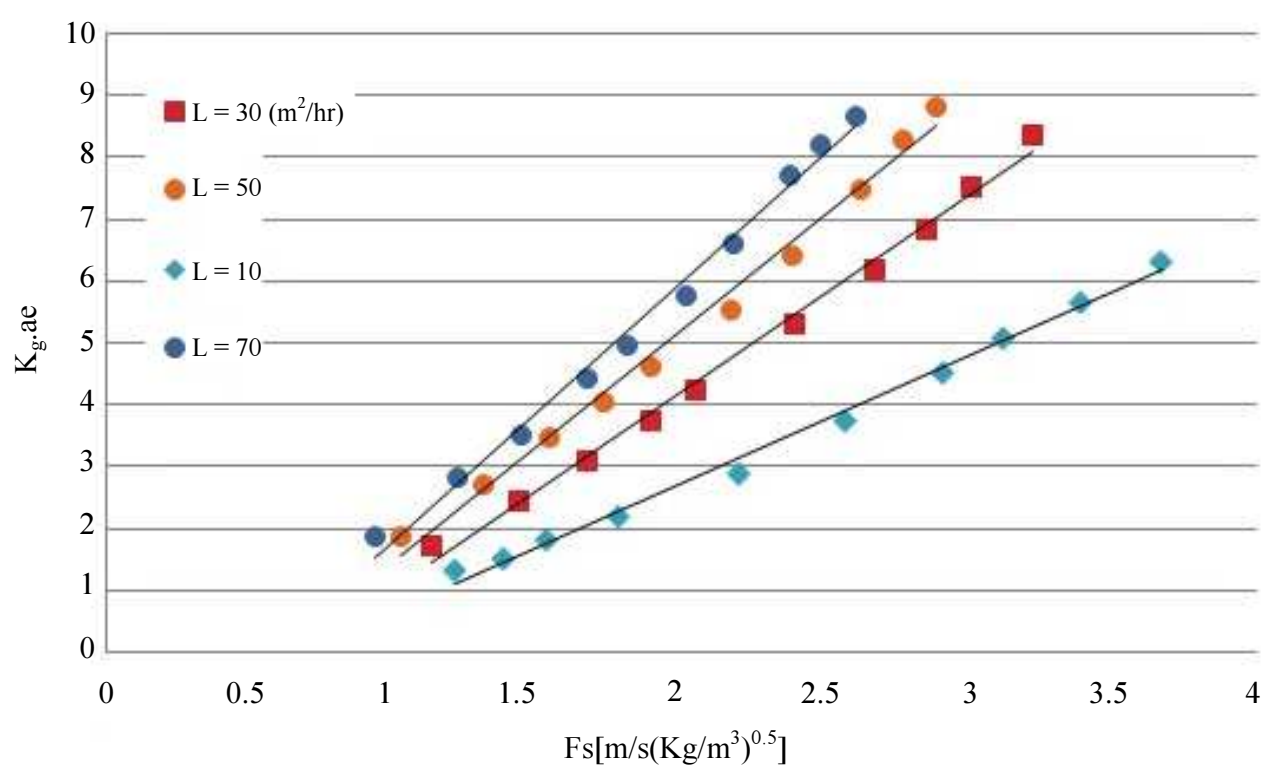

Fig. 3: Kgae per $F_{s}$ graph for gas capacity coefficient, $0.2 \mathrm{~m}$ diameter column

\section{Result and Discussion}

In common, it was terminated that the heat transfer coefficients were more sensitive to the temperature diversity for downwards flows than for upwards flows. As well as, there was no considerable relic on temperature diversity on the heat transfer ratios for upwards flows. It was also found that the downwards and upwards vertical directions were almost autonomous of the temperature diversity. With regard to the tendency trace, it was found that in common, it reduced with an enhance in temperature diversity but reduced with an enhance in mass flux and vapour quality. In addition, it was found that the heat transfer coefficient reduced with an enhanced in this temperature diversity. The orption procedure is forcefully effected by the impressive contact area. Very good compromise is achieved between the empirical and simulated consequences (number of mass transfer units $N T U \mathrm{~m}$ ). Common studies largely concentrate on dehumidification system under particular heat and mass transfer capability. In addition, a simulation model is expanded, which is accredited by experiential data and past research consequences. The heat and mass transfer capability of the system should be evaluated in the sketching procedure of flow path configuration to take an impressive proficiency for different range of NTUm. The result of liquid viscosity $(\mu \mathrm{L})$ on both the operative mass transfer area (ae) and the liquid film mass transfer factor $(\mathrm{kL})$ of packings is needed to auspicate mass transfer rate and plan the absorber and stripper. The evaporator and absorber are relative parts inside an Absorption Heat Transformer, because the refrigerant attains a high latent heat, which is absorbed by the strong binary mixture at high pressure for taking the beneficial heat (Kunze et al., 2015). Their heat transfer coefficients effect on the design and execute of an Absorption Heat Transformer. The inconstants investigated for this analysis were the heating temperature, the mass flux rate, pressure and condensations. The parameter explaining gas-liquid mass transfer severity (volumetric mass transfer coefficient $\mathrm{kLa}$ ) becomes than the key parameter (Chabanon and Favre, 2017). These popular equations brief the physical and thermophysical attributes of the air, the solution and the contactor, which make them able to be applied for parametric studies prepared they are fitted in a wide range of experiential data that contain all the properties involved (van der Ham et al., 1994). The experiential data taken at different air superficial velocities and solution flow rates were coordinated to the general relationships and collations between the predicted and experiential consequences for both ratios are within $\pm 10 \%$, for both dehumidification and regeneration operations. As well as, the computed values of the outlet air humidity relation and temperature agree well with the experimental data for both procedures (Giorgetti et al., 2017). A dimensionless group relationship of mass transfer coefficient is expanded and assessed. It was found that tendency notably effected the flow templates and the heat transfer coefficients (Dubois et al., 2017).

\section{Conclusion}

One of the effective parameters in mass transfer is the effective interfacial area (Yoon et al., 2009). In this 
article, the Nakajima et al. model was used to calculate $a_{e}$. Through calculating the effective interfacial area, the mass transfer coefficients were calculated, then the experimental $K_{g}$ values were compared to Zech, Shi, Shulman, Billet, Onda, Grouffmodels (Pinto et al., 2016). The finding showed that in the Onda, Grouff, Billet models, the $K_{g}$ values were higher than the experimental values and in the Shi and Shulman models were less than the experimental values. However, the Zech model had a relatively better prediction compared to other models and the obtained $K_{g}$ values from this model were closer to the experimental values. The Zech model's calculated error with the experimental values was $7 \%$.

In order to find the effect of column's diameter on mass transfer coefficients, experiments under equal conditions in a column with $0.1 \mathrm{~m}$ diameter were conducted.

Results showed that as the column's diameter decreases, the $\mathrm{K}_{\mathrm{g}}$. ae increases. One of the reasons for the increase of $\mathrm{K}_{\mathrm{g}}$.ae is that as the column's diameter decreases, liquid distribution is better and as a result, the mass transfer interfacial area increases. The other reason is the effect of the column's wall surface on mass transfer. As the diameter size decreases, the column's wall has more effectiveness on in creating an interfacial area for mass transfer, therefore, as the mass transfer interfacial area increases, $\mathrm{K}_{\mathrm{g}}$. ae increases.

Results of the volume fraction dispensations of material components on the thermal responds, containing the temperature alteration, the movement and the stresses dispensations were considered (Kolev, 2006). The special equations for the heat and mass transfer coefficients can be applied to do parametric studies at various air surface velocities and solution flow rates with very well precision. Conclusions from this article can help amend the system plan and practice procedures of air-solution contactors. It is visible that the mass transfer coefficient enhances with the enhance of water/air mass flow ratio, but reduces with the enhance of inlet water temperature and inlet air enthalpy. The relic of pressure on heat and mass transfer is connected with air mass flow. The heat and mass transfer between the antifreeze solution and air at low ambient temperatures is a key point for proficiency increment.

\section{Author's Contributions}

All authors contributed to design the study, write and revise the manuscript.

\section{Ethics}

The present Study and ethical aspect was approved by Isfahan University of Technology. The present study was approved by Isfahan University of Technology.

\section{References}

Aferka, S., A. Viva, E. Brunazzi, P. Marchot and D. Toye, 2011. Tomographic measurement of liquid hold up and effective interfacial area distributions in a column packed with high performance structured packings. Chem. Eng. Sci., 66: 3413-3422. DOI: 10.1016/j.ces.2011.01.022

Alix, P. L. Raynal, F. Abbe, M. Meyer and D. Rouzineau, 2011. Mass transfer and hydrodynamic characteristics of new carbon carbon packing: Application to $\mathrm{CO}_{2}$ post-combustion capture. Chem. Eng. Res. Design, 89: 1658-1668.

DOI: $10.1016 /$ j.cherd.2010.09.023

Andreev, B.M., E.P. Magomedbekov, A.A. Raitman, M.B. Pozenkevich and A.V. Horoshilov, 2007. Hydrogen isotope separation by chemical isotope exchange method in gas-liquid systems. Separation of Isotopes of Biogenic Elements in Two-phase Systems.

Bartelmus, G., A. Gancarczyk and M. Stasiak, 1998. Hydrodynamics of cocurrent fixed-bed three-phase reactors.: Part I. The effect of physicochemical properties of the liquid on pulse velocity. Chem. Eng. Process.: Process Intensificat., 37: 331-341. DOI: $10.1016 / \mathrm{S} 0255-2701(98) 00036-1$

Chabanon, E. and E. Favre, 2017. 3.9 Membranes contactors for intensified gas-liquid absorption processes. Comprehensive Membrane Sci. Eng., 3: 249-281.

DOI: 10.1016/B978-0-12-409547-2.12250-4

Chau, P.C., 1987. Local liquid-solid mass transfer measurement in a trickle film flow model using an electrochemical technique. Int. J. Heat Mass Transfer, 30: 2305-2317. DOI: 10.1016/0017-9310(87)90223-7

Coker, A.K., 2010. Packed Towers. In: Ludwig's Applied Process Design for Chemical and Petrochemical Plants, Coker, A.K. (Ed.), Gulf Professional Publishing, Oxford, ISBN-10: 0080942091, pp: 483-678.

Darakchiev, R., S. Darakchiev, D. Dzhonova-Atanasova and S. Nakov, 2016. Ceramic block packing of Honeycomb type for absorption processes and direct heat transfer. Chem. Eng. Sci., 155: 127-140. DOI: 10.1016/j.ces.2016.07.028

Dubois, L., S. Laribi, S. Mouhoubi, G. De Weireld and D. Thomas, 2017. Study of the post-combustion $\mathrm{CO}_{2}$ capture applied to conventional and partial oxyfuel cement plants. Energy Proc., 114: 6181-6196. DOI: 10.1016/j.egypro.2017.03.1756

Dubrawski, K., S. Tebianian, H.T. Bi, J. Chaouki and N. Ellisa et al., 2013. Traveling column for comparison of invasive and non-invasive fluidization voidage measurement techniques. Powder Technol., 235: 203-220. DOI: 10.1016/j.powtec.2012.10.031 
Fan, X., J. Li, D. Qiu and T. Zhu, 2018. Production of ammonia from plasma-catalytic decomposition of urea: Effects of carrier gas composition. J. Environ. Sci., 66: 94-103. DOI: 10.1016/j.jes.2017.05.033

Giorgetti, S., L. Bricteux, A. Parente, J. Blondeau and F. Contino et al., 2017. Carbon capture on micro gas turbine cycles: Assessment of the performance on dry and wet operations. Applied Energy, 207: 243-253. DOI: 10.1016/j.apenergy.2017.06.090

Gładyszewski, K. and M. Skiborowski, 2018. Additive manufacturing of packings for rotating packed beds. Chem. Eng. Process. Process Intensificat., 127: 1-9. DOI: $10.1016 /$ j.cep.2018.02.024

Goldstein, R.J., W.E. Ibele, S.V. Patankar, T.W. Simon and T.H. Kuehn et al., 2006. Heat transfero-a review of 2003 literature. Int. J. Heat Mass Transfer, 49: 451-534.

DOI: 10.1016/j.ijheatmasstransfer.2005.11.001

Gómez-Castro, F.M., D. Schneider, T. Päßler and U. Eicker, 2018. Review of indirect and direct solar thermal regeneration for liquid desiccant systems. Renewable Sustainable Energy Rev., 82: 545-575. DOI: 10.1016/j.rser.2017.09.053

Khamadieva, R. and U. Böhm, 2006. Mass transfer to the wall of a packed and unpacked bubble column operating with Newtonian and non-Newtonian liquids. Chem. Eng. J., 116: 105-113.

DOI: $10.1016 /$ j.cej.2005.11.003

Kishimoto, M., H. Iwai, M. Saito and H. Yoshida, 2011. Quantitative evaluation of solid oxide fuel cell porous anode microstructure based on focused ion beam and scanning electron microscope technique and prediction of anode overpotentials. J. Power Sources, 196: 4555-4563.

DOI: 10.1016/j.jpowsour.2010.12.100

Kolev, N., 2006. Investigation of the Main Performance Characteristics of Packed Bed Columns. In: Packed Bed Columns, Kolev, N. (Ed.), Elsevier, Amsterdam, ISBN-10: 0080463924, pp: 95-148.

Kunze, A.K., P. Lutze, M. Kopatschek, J.F. Maćkowiak and A. Górak, 2015. Mass transfer measurements in absorption and desorption: Determination of mass transfer parameters. Chem. Eng. Res. Design, 104: 440-452. DOI: 10.1016/j.cherd.2015.08.025

Li, Y., J.F. Klausner, R. Mei and J. Knight, 2006. Direct contact condensation in packed beds. Int. J. Heat Mass Transfer, 49: 4751-4761.

DOI: 10.1016/j.ijheatmasstransfer.2006.06.013

Longo, G.A. and A. Gasparella, 2005. Experimental and theoretical analysis of heat and mass transfer in a packed column dehumidifier/regenerator with liquid desiccant. Int. J. Heat Mass Transfer, 48: 5240-5254. DOI: 10.1016/j.ijheatmasstransfer.2005.07.011
Onda, K., H. Takeuchi and Y. Okumoto, 1968. Mass transfer coefficients between gas and liquid phases in packed columns. J. Chem. Eng. Jpn., 1: 56-62. DOI: $10.1252 /$ jcej. 1.56

Oueslati, A., A. Megriche, A. Hannachi and M. Elmaaoui, 2017. Performance study of humidification-dehumidification system operating on the principle of an airlift pump with tunable height. Process Safety Environ. Protect., 111: 65-74. DOI: 10.1016/j.psep.2017.05.018

Parrish, D.D. and F.C. Fehsenfeld, 2000. Methods for gas-phase measurements of ozone, ozone precursors and aerosol precursors. Atmos. Environ., 34: 19211957. DOI: $10.1016 / \mathrm{S} 1352-2310(99) 00454-9$

Peychès-Bach, A., M. Moutounet, S. Peyron and P. Chalier, 2009. Factors determining the transport coefficients of aroma compounds through polyethylene films. J. Food Eng., 95: 45-53. DOI: 10.1016/j.jfoodeng.2009.04.012

Pinto, D.D.D., R. Emonds and G.F. Versteeg, 2016. Experimental determination of mass-transfer coefficients and area of dumped packing using alkanolamine solvents. Energy Proc., 86: 219-228. DOI: $10.1016 /$ j.egypro.2016.01.023

Schaefer, C.E., R.R. Arands, H.A. van der Sloot and D.S. Kosson, 1997. Modeling of the gaseous diffusion coefficient through unsaturated soil systems. J. Contaminant Hydrol., 29: 1-21. DOI: 10.1016/S0169-7722(96)00097-6

Seibert, F., E. Chen, M. Perry, S. Briggs and G. Rochelle, 2011. UT/SRP $\mathrm{CO}_{2}$ capture pilot plantOperating experience and procedures. Energy Proc., 4: 1616-1623. DOI: 10.1016/j.egypro.2011.02.032

Shulman, H. L. and J.J. de Gouff, 1915. Mass transfer coefficients and interfacial areas for 1-inch raschig rings. Ind. Eng. Chem., 44: 1915-1922.

DOI: $10.1021 /$ ie $50512 \mathrm{a} 048$

Shulman, H.L., C.F. Ullrich, A.Z. Proulx and J.O. Zimmerman, 1955. Performance of packed columns. 2. Wetted and effective interfacial areas, gas- and liquidphase mass transfer rates. AIChE J., 1: 253-258. DOI: 10.1002/aic.690010220

Sugiyama, T., M. Tanaka, K. Munakata, Y. Asakura and L. Doerr, 2008. Development of an improved LPCE column for the TLK facility with the help of the channeling stage model. Fus. Eng. Design, 83: 1442-1446. DOI: 10.1016/j.fusengdes.2008.06.005

Sun, Z., C. Liu, G. Yu and X. Yuan, 2011. Prediction of distillation column performance by computational mass transfer method. Chinese J. Chem. Eng., 19: 833-844. DOI: 10.1016/S1004-9541(11)60063-3

Treybal, E.R., 1968. Mass Transfer Operation. 3rd Edn., McGraw-Hill, New York USA. 
van der Ham, A.G.J., W. Prins and W.P.M. van Swaaij, 1994. A small-scale regularly packed circulating fluidized bed: Part I: Hydrodynamics. Powder Technol., 79: 17-28. DOI: 10.1016/0032-5910(93)02805-K

Wang, Y., Y. Li, S. Weng and Y. Wang, 2007. Numerical simulation of counter-flow spray saturator for humid air turbine cycle. Energy, 32: 852-860. DOI: 10.1016/j.energy.2006.05.008

Weiss, C. and U. Wieltsch, 2005. Laser optical flow measurements and computational fluid dynamic calculation of spray tower hydrodynamics. Chem. Eng. Res. Design, 83: 492-507. DOI: $10.1205 /$ cherd.04071

$\mathrm{Xu}, \mathrm{Z}$., Y. Lu and Y. Xie, 2015. Hydrodynamic and heat and mass transfer performances of novel ceramic foam packing to humidification tower. Applied Thermal Eng., 87: 707-713.

DOI: 10.1016/j.applthermaleng.2015.05.043

Yoon, H., M. Oostrom, T.W. Wietsma, C.J. Werth and A.J. Valocchi, 2009. Numerical and experimental investigation of DNAPL removal mechanisms in a layered porous medium by means of soil vapor extraction. J. Contaminant Hydrol., 109: 1-13.

DOI: 10.1016/j.jconhyd.2009.07.001
Zaidiza, D.A., B. Belaissaoui, S. Rode, T. Neveux and E. Favre, 2015. Adiabatic modelling of $\mathrm{CO}_{2}$ capture by amine solvents using membrane contactors. J. Membrane Sci., 493: 106-119.

DOI: $10.1016 /$ j.memsci.2015.06.015

Zhang, L., E. Hihara, F. Matsuoka and C. Dang, 2010. Experimental analysis of mass transfer in adiabatic structured packing dehumidifier/regenerator with liquid desiccant. Int. J. Heat Mass Transfer, 53: 2856-2863.

DOI: 10.1016/j.ijheatmasstransfer.2010.02.012

Zhang, L.Z., 2012. Progress on heat and moisture recovery with membranes: From fundamentals to engineering applications. Energy Convers. Manage., 63: 173-195. DOI: 10.1016/j.enconman.2011.11.033

Zivdar, M., M. Haghshenas Fard and R.G.H. Prince, 2006. Evaluation of pressure drop and mass-transfer characteristics of a structured packing for production and separation of food flavours: Part II: Masstransfer characteristics. Food Bioproducts Process., 84: 206-212. DOI: 10.1205/fbp.04003

\section{Research Highlights}

- Measurement of mass transfer coefficients in a column with random packing (Onda et al., 1968)

- Measurement of liquid retention 